\title{
Poeta geni(t)al. El difuso límite entre erotismo y pornografía en el carmen 50 de Catulo
}

\begin{abstract}
Resumen
El presente trabajo se inscribe en una línea interpretativa según la cual buena parte de la literatura erótica antigua podría ser leída también en clave 'pornográfica'. En particular, está centrado en el carmen 50 del poeta neotérico Cayo Valerio Catulo. En dicha composición pareciera aludirse a la práctica onanista del yo poético, alusión que dejaría de ser tal para constituirse en una referencia explícita del mismo. Analizando aquellos términos o estrategias discursivas que requieren y alientan el trabajo inferencial del lector, se espera poder corroborar la lectura propuesta.
\end{abstract}

\section{Geni(t)al poet. The diffuse limit between eroticism and pornography in Catullus' carmen 50}

\begin{abstract}
The present work is inscribed in an interpretative line according to which much of the ancient erotic literature could be read in 'porno-graphic' key. In particular, it is centered on the carmen 50 of the neoteric poet C. V. Catullus. In this composition it seems to allude to the onanist practice of the poetic-self, an allusion that would cease to be such to constitute an explicit reference to it. Analyzing those terms or discursive strategies that require and encourage the inferential work of the reader, we hope to be able to corroborate the proposed reading.
\end{abstract}

\section{Palabras-clave}

Catulo

carmen 50

porno-grafía cooperación textual

\section{Keywords}

Catullus carmen 50 porno-graphy textual cooperation 
1. Zimmermann, quien trata de manera concisa y general el tema de la sexualidad y del erotismo en el ámbito específico de la literatura griega, entiende por 'erotismo' "la representación del amor en todas sus formas, teniendo en cuenta el componente sexual en una cuidadosa configuración literaria" (2003:155). Por su parte, Hydé (1969:8) estima que lo que define a la pornografía como tal es la representación del sexo, poniendo de relieve su capacidad para estimular los apetitos sexuales. En la misma línea de pensamiento, Lissardi sostiene que la pornografía "es un tipo de discurso cuyo único objetivo consiste en la representación del acto sexual humano" (2013:89) y que el cuerpo humano representado funciona "estimulando en nosotros el deseo de concupiscencia, invitándonos a la voluptuosidad" (2013:90). Reflexionando sobre la distinción entre lo erótico y lo pornográfico, Marzano (2006:33) considera que el erotismo, al contrario, busca perpetuar el misterio del deseo y del sexo, mientras que la pornografía entrega a la mirada de un espectador voyeur un cuerpo fragmentado y carente de rostro que disipa el enigma del encuentro sexual.

2. "La loro amicizia divampò, per così dire, in un grazioso duello poetico. Si conoscevano certo e si stimavano anche prima (...) [Catullo] scrisse un poema col quale significava la sua ammirazione e il suo affetto" (Rizzo, 1992:175; el autor está citando un libro de G. Pascoli, La poesia lirica in Roma, que no consigna en sus referencias bibliográficas).

3. "At a banquet (...) Catullus and Calvus had engaged in a contest

of improvisation, in which Catullus was so newly charmed with his friend's genius" (Merrill, 1893:83).

4. "Para mí, los síntomas de homosexualidad de Catulo se presentan en poemas como éste, más espontáneos, más originales, menos de escuela que los de Juvencio" (Soler Ruiz, 2000:77).

5. "A glimpse of the novi poetae at play; Catullus has spent an evening in gay improvisation with the lively little Calvus" (Fordyce, 1961:215).

6. "El poema 50 nos revela que la experiencia literaria -los poemas intercambiados con Calvo- afecta el cuerpo de Catulo de igual modo que si se tratara de una enfermedad con el poder de enfebrecer a su víctima" (Zaina, 1997:306).

\section{I}

Un buen número de poemas del corpus catuliano posee un elevado tinte erótico. Entre ellos hay algunos en los cuales la alusión a la sexualidad requeriría ser interpretada como una referencia explícita al acto sexual mismo. En concreto, el carmen 50 pareciera aludir a la práctica onanista del yo poético. La intención que persigo en el presente trabajo consiste en mostrar en qué medida este poema puede ser leído como poema 'porno-gráfico'.

Siendo consciente de la dificultad que entraña pensar un fenómeno cultural de la antigüedad grecolatina con un concepto que no tiene equivalente en esa cultura, voy a entender por 'porno-grafía' la representación explícita o implícita del acto sexual, mientras que lo 'erótico' quedaría reservado para indicar la representación del deseo sexual. Etimológicamente, pues, el concepto de 'porno-grafía', aplicado a la literatura, designaría la escritura del coito, del acto sexual, en tanto representación del sexo carnal, mundano, gozoso. ${ }^{1}$

Asumiendo, como señala Umberto Eco (1981, 1996), que todo texto es una máquina perezosa que requiere la colaboración del lector para generar sentido, parto de la hipótesis según la cual el poeta inscribe en el cuerpo textual determinadas pautas interpretativas. Pautas que se espera el lector, resquebrajando la superficie significante del texto, sepa descifrar para acceder a ciertos contenidos sugeridos por el mismo. De este modo, la instancia de recepción resulta ser tan relevante en la interpretación textual como lo es la instancia enunciativa. Conjugando ambas instancias, el intérprete de aquellos poemas catulianos que presentan esta intención 'sexo-alusiva' estaría en mejores condiciones para descubrir, construir y gozar de la 'porno-grafía' velada que los estructura, haciendo de los versos alusivamente sexuales versos efectivamente 'porno-gráficos'.

Con sutileza de alejandrino, Catulo en el carmen 50 pone en escena una situación homoerótica. Rizzo (1992) considera que este poema catuliano presenta una relación de amistad y admiración entre dos poetas que pertenecen al mismo movimiento literario, ${ }^{2}$ lo cual no contradice la opinión estilada por Merrill (1893) en su edición decimonónica del poemario del genio veronense. ${ }^{3}$ Por su parte, Soler Ruiz (2000), si bien no trasciende esta línea interpretativa, señala el componente homosexual que lo motiva, por lo que habla de una relación de 'amistad-amor' entre los poetas, ${ }^{4}$ cuestiones ambas que ya habían sido mencionadas por Fordyce (1961) en su clásico comentario a la obra catuliana. ${ }^{5}$ Tanto Zaina (1997) como Galán (2013) parecen adscribir a tal idea, mencionando la pasión amorosa o erótica, respectivamente, que se desata en el joven veronés por su amigo y colega. ${ }^{6}$ Como se verá a continuación, en el presente trabajo propongo una interpretación sustancialmente diferente a estas.

Según Eco (1998), hay tres grandes posibilidades de interpretación de un texto. Por un lado, hay interpretaciones 'legítimas', en las que el texto pide ser interpretado de una determinada manera, es decir, hay marcas o señales explícitas que guían su correcta decodificación; por otro lado, hay interpretaciones 'legitimables', en las que el texto puede ser interpretado en función de marcas o señales implícitas que habilitan una decodificación consistente; por último, hay interpretaciones 'aberrantes', que son aquellas que el texto no pide de ninguna manera, es decir, no hay forma de sostener ciertas interpretaciones basándose en el material textual. Dicho esto, téngase en cuenta que en las páginas que siguen voy a proponer una interpretación legitimable del carmen 50. 
El carmen 50 de Catulo puede dividirse en tres partes: en la primera, el yo poético se dirige a su amigo Licino para recordarle lo que hicieron la víspera: pasarla bien componiendo versos entre chistes y vino (vv. 1-7); en la segunda, el yo poético le confiesa al amigo que lo tiene locamente erotizado (vv. 7-17); en la tercera, exhorta a Licinio a que no menosprecie su apetito sexual, a fin de evitar a la vehemente Némesis (vv. 18-21). ${ }^{7}$

El poema puede ser entendido como una 'epístola de amor' diferida a través de la cual el yo poético le confiesa impersonalmente su pasión amorosa al amigo. El poema que le envía será, justamente, el medio por el cual este habrá de enterarse de los sentimientos íntimos de su colega. Misiva 'amorosa' que así comienza:

\author{
Hesterno, Licini, die otiosi \\ multum lusimus in meis tabellis, \\ ut convenerat esse delicatos. (1-3) \\ En el día de ayer, Licinio, desocupados, \\ mucho jugamos entre mis tablillas, \\ como se había convenido que fueran los delicados. ${ }^{8}$
}

Licinio Calvo, al igual que Catulo, pertenecía al movimiento neotérico. ${ }^{9}$ El yo poético le recuerda el labor que estuvieron realizando juntos el día anterior: en tanto poetas sin un cargo público, viven alejados de las preocupaciones de la vida política, son otiosi. Como tales se dedican a componer versos de manera lúdica ("multum lusimus in meis tabellis"), siguiendo los principios compositivos de la poética alejandrina que, entre otras cosas, exhortan a forjar versos suaves, amenos. Quizás sea este rasgo poético aquello a lo que quiere aludir el poeta con ese carácter de delicati que exhiben él y su colega ("ut convenerat esse delicatos" $)^{10}$

Si prestamos atención al uso de otros términos, notaremos que estos también tienen más de una acepción. El verbo ludo, por ejemplo, suele tener connotaciones sexuales. En este sentido, hace referencia al acto sexual (puede ser traducido al español rioplatense por 'coger') cuando resulta placentero para ambos participantes. ${ }^{11}$ Por otra parte, delicatus no sólo hace referencia al comportamiento de una persona, sino que también podría referirse a sus modales y gustos en clave genérica, en este caso varones con modales y gustos de mujer, es decir, afeminados. ${ }^{12}$

En la intimidad, pues, cuando no tiene que poner en juego su imagen social, el yo poético se permitiría hablarle a su amigo de su condición sexual: es delicatus, no sólo como artista sino también como hombre. Este yo poético que se muestra sexualmente duro e inflexible en el carmen 16 contra Aurelio y Furio, a quienes estigmatiza por su dudosa masculinidad, ${ }^{13}$ pareciera relajarse aquí y expresar su atracción sexual por Licinio Calvo:

Scribens versiculos uterque nostrum

ludebat numero modo hoc, modo illoc,

reddens mutua per iocum atque vinum. (4-6)

Escribiendo versitos, cada uno de nosotros

jugaba ya con un ritmo ya con otro,

entregando[nos] mutuamente por la diversión y el vino.
7. Soler Ruíz (2000:77) propone el siguiente esquema de composición: apóstrofe a Licinio, que establece la situación en que se encontraban los dos amigos (vv. 1-6); signa amoris (vv. 7-13); regalo poético de Catulo y amenazas (vv. 14-21).

8. Todas las citas del texto latino siguen la edición de Schuster (1958); la traducción de los pasajes citados pertenece al autor del presente trabajo. 9. Dentro del corpus catuliano, Licinio Calvo es también mencionado en los carmina 14 y 53.

10. Los poetas alejandrinos (Calímaco, Apolonio, Teócrito, Arato) estilaron una serie de principios poéticos que pusieron en práctica en sus propias producciones. Estos principios eran la agrypnía, la oligostikhía, la leptótes y la polyeideía, principios que fueron llevados a Roma por los poetae novi o neotéricos y que en suelo latino se conocían como labor limae, brevitas, levitas y variatio, respectivamente; cfr. Fraschini (1966:157-172). Para un estudio detallado de la corriente neotérica puede consultarse Lyne (2007).

11. Cfr. Adams (1972:162); Uría

Varela (1997:361) señala que a partir de Catulo "la acepción sexual del término se afianza en la lengua erótica".

12. Fordyce (1961:216) desarrolla un extenso e informado análisis del término que no contempla la acepción aquí propuesta, la cual sí parece estar referenciada en el OLD (s.v. delicatus 5.b.: "(of actions, attitudes, etc.) elegant, polite; effeminate"), aunque no ejemplifica con este ni con ningún otro pasaje del corpus catuliano. Por lo tanto, la acepción propuesta aquí posee necesariamente un carácter conjetural basada en y sujeta a la coherencia argumentativa del presente trabajo.

13. Manwell (2007) indica que la dureza juega un rol importante en la visión que tiene Catulo de la identidad masculina, porque es la normativa en el mundo competitivo de los hombres, sobre todo para los de la élite, en la Roma tardorrepublicana. En este sentido, el objetivo último de las invectivas catulianas consiste en mostrar la masculinidad propia y el afeminamiento del rival. Esto se ve claramente en el carmen 16, en el que la acusación contra Furio y Aurelio de pathicusy cinaedus implica, en términos éticos que estos no pueden exhibir modestia o piedad, porque son molles mares. Por su parte, el poeta se muestra pío y casto, y aunque exhibe su mollitia en el carmen 5, eso no evidencia que él sea un mollis más. Si algo pone de manifiesto la invectiva sexual de Catulo contra sus rivales, es que su noción de identidad masculina no es monolítica ni fácil de definir. Según Wiseman (2007:354) no hay contradicción en Catulo, pues si bien puede humillar a sus enemigos tratándolos de pathici y cinaedi él mismo en otro contexto puede ser delicatus, sin adoptar esto un tono peyorativo. 
14. Van Dijk (1985:112) entiende por 'marco' o 'script' "nuestro conocimiento del mundo" en relación con la circunstancia general que engloba los hechos presentados en las cláusulas, mientras que para Givón (1993) tiene que ver con "el conocimiento culturalmente compartido, convencional y genérico acerca de esquemas de acción secuencial" (1993:203), conocimiento que contribuye a la atribución tanto de coherencia local como de coherencia global al texto. Para Borzi, quien parece seguir en este punto la línea de van Dijk, se trata de "unidades de información convencional sobre determinadas situaciones y acontecimientos típicos", que "especifican cuando una cosa es parte integrante de una circunstancia como 'pagar' lo es de 'ir a la taberna'" (2012:123n.3).
Otra vez, lo que parece ser una alusión a la poética alejandrina ("scribens versiculos") escondería connotaciones sexuales, a juzgar por la totalidad del mensaje. Escribir 'versitos' puede estar refiriendo a la brevitas de la composición neotérica, pero tengamos también en cuenta la situación en que se están componiendo esos versitos: mientras componen, uno y otro ("uterque nostrum") comienzan a jugar con el pie métrico ("ludebat numero modo hoc modo illoc"), por lo que se establece una suerte de ida y vuelta compositiva que bajo los efectos del vino se hace cada vez más jocosa ("reddens mutua per iocum atque vinum").

Este "ludebat" remite al "lusimus" del segundo verso, con la misma acepción. Y si nos guiamos por el script de la situación representada, ${ }^{14}$ notaremos que en el iocum de la composición está implicada la escritura, es decir, la actividad manual, la acción de la manus. No sería, pues, del todo descabellado interpretar que ese movimiento desordenado de 'jugar" "modo hoc modo illoc", con el cual cada uno comienza a tener sensaciones voluptuosas, esté aludiendo a un movimiento pre-onanístico, en función del cual se van estimulando superficialmente y ya más rápida ya más lentamente sus zonas erógenas. Extensivamente, en ese movimiento, liberados ambos por el efecto de la bebida espirituosa, se terminarían manoseando mutuamente ("reddens mutua"). Situación que no habría pasado del roce, del mero estímulo erótico ("multum lusimus"), sin haberse consumado en ningún acto sexual. En este sentido, el uso del diminutivo en el verso 4 ("versiculos") podría estar motivado por la intención de expresar que el miembro viril de cada uno no llegó a alcanzar una erección total, la dilatación orgásmica.

En el siguiente bloque de versos, siguiendo esta lectura, el yo poético manifestaría su apremiante necesidad de descarga libidinal:

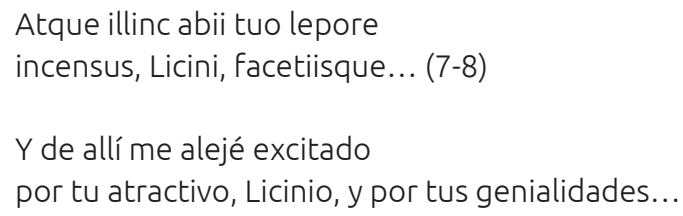

Los primeros seis versos presentaron una situación, un marco narrativo, que se plantea en términos causales respecto de lo que sigue: habiéndose alejado de Licinio, el yo poético quedó suspenso en un fuerte estado de excitación a causa del contacto lúdico con su amigo. Esta excitación no sólo es física o emotiva ("tuo lepore incensus"), sino que es a la vez intelectual ("incensus facetiis"). El deseo sexual posee entonces en el yo poético un canal de doble entrada: Licinio lo excita como poeta y como persona.

Pero la necesidad de satisfacción sexual es incontrolable, no puede dilatarla por más tiempo, a lo cual respondería el hecho de que se multipliquen en su relato los términos con connotaciones sexuales:

Ut nec me miserum cibus iuvaret, nec somnus tegeret quiete ocellos, sed toto, indomitus furore, lecto versarer cupiens videre lucem, ut tecum loquerer simulque ut essem. (9-13) 
De modo que, desdichado de mí, ni la comida me complacía,

ni el sueño cubría tranquilamente mis ojitos,

sino que, incontrolable por el delirio, por toda la cama

me agitaba, deseando ver la luz [del día],

para hablar y al mismo tiempo estar con vos.

El yo poético es presa de un omnívoro deseo sexual ("indomitus furore"), de una fulminante obsesión por Licinio, a tal punto que muestra algunos de los síntomas del morbus amoris: no come ("nec cibus iuvaret") ni puede dormir ("nec somnus tegeret quiete ocellos"), sino que insomne da vueltas en el lecho deseando ("cupiens") tener algún tipo de contacto físico con Licinio ("ut tecum loquerer simulque ut essem"). ${ }^{15}$

Si vinculamos el tema del descontrol fisiológico ("indomitus furore") causado por el furor amoris con el motivo del morbus amoris, podemos pensar que el yo poético quedó tan incensus que su deseo no encontró otra línea de fuga más que la masturbación. Si bien en el texto no hay términos que designen o connoten la práctica onanista masculina, sí podemos recurrir a la funcionalidad semántica que tiene el motivo implícito de la manus presente en el primer bloque de versos. Adams señala que, además de los verbos usados para designar concretamente las prácticas masturbatorias, existen también expresiones coloquiales que las aluden, como por ejemplo la expresión amica manus. ${ }^{16}$ Los versos siguientes parecen apoyar esta hipótesis:

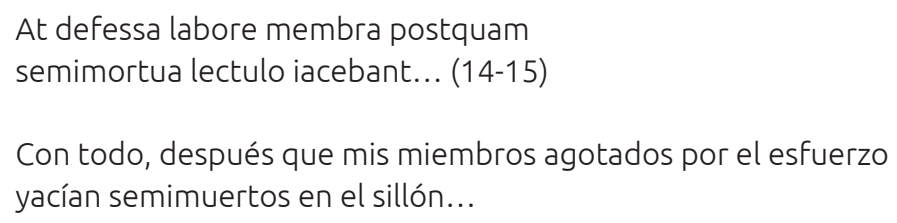

En efecto, estos versos parecerían estar aludiendo al estado post-masturbatorio, aquel en el cual el cuerpo cae agotado, extenuado ("defessa labore membra"). Por el estado semicadavérico ("semimortua lectulo iacebant") en que se encuentra el cuerpo del yo poético, parece éste haberse extralimitado en su acto onanístico. Lo que empezó como una situación distendida y jocosa entre amigos derivó en una obsesión que exhibe los síntomas de una pasión sexual.

Con lo último que le resta de fuerza, el cuerpo del yo poético se arrastra del lecho al sillón, al lectulus, para componerle un poema al objeto de su deseo, Licinio:

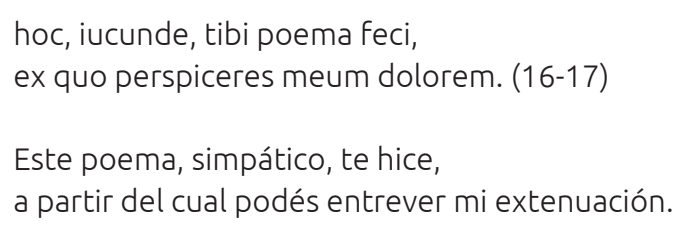

Este poema, dijimos, es una suerte de 'epístola de amor' donde el yo poético le confesaría al amigo su deseo de tener contacto sexual con él, a quien llama "iocunde", simpático, encantador. ${ }^{17}$ La existencia misma de su amigo es una celebración de lo poético y de lo vital, del juego y del sexo. Pero el yo poético se anima a confesar su deseo y su agotamiento físico y mental ("meum dolorem") en diferido: sólo una vez alejado de Licinio Calvo es capaz de escribirle un poema 'confesional'.
15. La vinculación de la pasión amorosa con los estados enfermizos comenzó a tomar cuerpo conceptual a partir de los tratados hipocráticos y de la filosofía (Platón, Aristóteles). Con anterioridad a estos, lo enfermizo era una nota más del amor en tanto pasión, pero de ningún modo era considerado como tal; cfr. Cabello Pino (2012).

16. Cfr. Adams (1972:209).
17. En el carmen 14a también llama a Licinio iocundus, sólo que lo hace en superlativo y por el cognomen: "iucundissime Calve"(v.2). 
18. Cfr. v. 2: multum, lusimus, meis, v. 4: nostrum, v. 5: numero, modo, modo, v. 6: mutua, iocum, vinum. La aliteración de este sonido llega al paroxismo en el carmen 5, composición 'erótica' que aparece atravesada por la dimensión sensual de las voluptuosas sensaciones orales provocadas por los miles de besos intercambiados lúdicamente con su amada Lesbia (cfr. v. 1: vivamus, mea, amemus, v. 2: rumores, senum, severiorum, v. 3 : omnes, aestimemus, v. 5: cum semel v. 8: mille, centum, v. 9: mille, centum, v. 10: cum, milia, multa, fecerimus, v. 11: conturbabimus, sciamus, v. 12: malus, v. 13: cum, tantum, basiorum)

19. Cfr. v. 7: tuo, v. 10: tegeret, quiete, v. 11: indomitus, v. 13: tecum, ut essem, v. 15: semimortua, lectulo.
Notemos lo siguiente. En la primera parte del carmen se repite insistentemente el sonido oclusivo bilabial / $\mathrm{m} /$ como si el poeta, lubricando su palabra, su boca, estuviese prefigurando un goce oral. ${ }^{18}$ En la segunda parte los que se repiten son los sonidos /te/ y / tu/ que hacen referencia al pronombre personal de segunda, que en este caso designarían a Licinio como objeto de deseo. ${ }^{19}$ Entonces, si en un primer instante el yo poético acalla el deseo sexual por su amigo, más tarde lo satisfará ejerciendo un tactus lascivus que lo conduce a la polución seminal.

Agotado, lánguido, postrado y con el deseo focalizado en Licinio Calvo, el yo poético se anima a pedirle que corresponda a su pasión sexual:

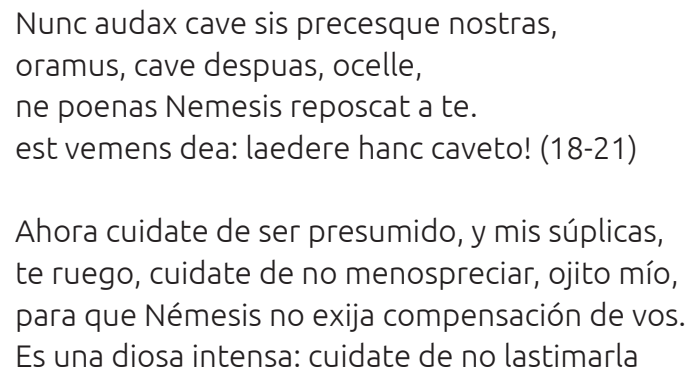

La estrategia consiste en hacerle ver a Licinio que lo mejor es consumar el deseo sexual en contacto con el cuerpo deseado, pues de lo contrario la satisfacción total de ese deseo resulta imposible. Se lo vive como una condena, como una pena, como una frustración ("poenas"). Pero como no sabe si Licinio también se fue excitado o incluso si se masturbó -como habría hecho él- hasta quedar exangüe, lo amenaza con Némesis, diosa vengativa, a quien, vehemente y apasionada ("vemens") como el yo poético, hay que evitar ofender ("laedere"). Lo más sensato será que la próxima vez que se encuentren corresponda sin ambages a su deseo accediendo él también.

En esta parte final no se repite ningún sonido, como sucedía en las dos primeras, pero se repite tres veces el mismo verbo: caveo. Y esta repetición puede responder, al menos, a una doble intención artística. $\mathrm{O}$ bien el verbo está usado haciendo valer su acepción jurídica de 'respetar', 'cumplir', y en este caso lo que habría que respetar o cumplir es una especie de foedus libidinis implícito, ese que se instituyó el día aquel en que se 'toquetearon', o bien está siendo empleado con el sentido de 'ser precavido', ' ponerse en guardia', ${ }^{20}$ con lo cual el yo poético le estaría sugiriendo a Licinio que, si traiciona el foedus libidinis, ${ }^{21}$ la próxima vez que se vuelvan a ver (de ahí el futuro de imperativo: "caveto") actuará como una Némesis que lo forzará a satisfacer su propio deseo sexual.

\section{III}

Cabe aclarar que ningún poema de Catulo representa explícitamente el acto sexual. Lo que hay son usos de ciertos términos 'obscenos' (pedico, irrumo, fututio, mentula, etc.) e innumerable alusiones que lo sugieren.

Es por esto que el rol del lector es aquí de fundamental importancia. La escena de sexo sólo existe si el lector colabora para construirla. El poeta inscribe en el cuerpo textual marcas que el lector debe descifrar, quebrando la superficie representacional del texto para acceder a aquellos contenidos latentes que lo 
hacen significativo. La significancia -afirma Barthes- "es el sentido en cuanto es producido sensualmente" (2003:100). Es el lector de los carmina, pues, quien debe finalmente producir esa significancia y gozar con/de los sentidos 'pornográficos' que estructuran algunos de los poemas del corpus, leyendo su reverso y transformando los versos eróticos en versos 'porno-gráficos'.

Pero, ¿en qué sentido se puede hablar de 'porno-grafía' en la antigüedad grecolatina? Como fue mencionado al principio de este trabajo, entiendo por 'porno-grafía' la representación explícita -o tal vez implícita- del acto sexual, mientras que lo 'erótico' haría referencia a la representación del deseo sexual.

La historia de la pornografía es quizás tan antigua como la literatura. Hydé (1969:7) y García Rodríguez (2001:3) remiten al origen griego del término, ${ }^{22}$ mientras que Loth (1969:67) señala que el origen literario de la pornografía occidental se remontaría a las canciones que se entonaban durante el desenfreno sexual que tenía lugar en las ceremonias dionisíacas. De estos festivales sexuales se originó la yambografía y el teatro griego. Especialmente, la pluma procaz de Aristófanes. Dado que vivía las relaciones sexuales como algo totalmente corriente, el público ante el cual se representaban las obras recibía con gozo las escenas de sexo. La 'porno-grafía' de los autores romanos, si bien basaron su producción artística en la poética griega, fue en cambio menos provocativa y desinhibida, porque la sociedad romana era más conservadora respecto de los excesos sexuales. ${ }^{23}$ Debido a esto, los poetas latinos desplegaron "una ligereza de toque casi helenístico en su pornografía" (Loth 1969:76), sutileza alusiva que estimula, en el oyente/lector, una modalidad específica de representación: el voyeurismo.

Veamos ahora cuáles son las marcas textuales que nos permitirían leer el carmen 50 de Catulo como un poema 'porno-gráfico'.

En principio, la elección del léxico. Como hemos visto, en la primera parte se repite el verbo ludo ("lusimus", "ludebat") que, como sabemos, tiene una fuerte connotación sexual. Además hay dos elipsis temporales. La primera separa el primer bloque de versos del segundo ("reddens mutua per iocum atque vinum", v. 6 / "atque illinc abii", v. 7), mientras que la segunda corta en dos el segundo bloque de versos ("ut tecum loquerer simulque ut essem", v. 13 / "at defessa labore membra", v. 14). En el primer caso, el atque marca la transición entre lo que habían hecho los dos amigos mientras estaban juntos y lo que siente el yo poético cuando se queda solo. O sea, se pasa de una situación de intimidad compartida a una escena de intimidad solitaria. En el segundo caso, el at opone dos situaciones: aquella en que el yo poético es presa del furor libidinis y aquella otra en que yace extenuado en el lecho. En ambos casos, entre el atque y lo que lo precede y el at y lo que lo precede habita el espacio semiótico de lo no dicho. Ese espacio vacío es un campo fértil que requiere la colaboración textual del lector. Lector al que se podría estar interpelando en el siguiente verso:

ex quo perspiceres meum dolorem (17)

A partir del cual podés entrever mi extenuación.

En concreto, el uso del verbo perspicere hace referencia al acto de ver. Según hemos apuntado más arriba, la mirada se constituye como el dispositivo esencial de la 'porno-grafía', en tanto construye un espectador/lector voyeur. ${ }^{24} \mathrm{El}$
22. El pornográphos sería, en griego tardío, el que escribe sobre la vida de las pórnai ('putas') y de sus clientes (cfr. Hydé, 1969:7, Marzano, 2006:32), aunque García Rodriguez (2001:3), basándose en las entradas de Liddell-ScottJones (1996), apunta que además de pórne existe pórnos, palabra que hace referencia al 'depravado', al 'sodomita'.

23. Cfr. Hydé (1969:64), Loth (1969:75-76).
24. En el poema hay menciones explícitas al órgano de la visión y al acto de ver. El yo poético menciona sus ocelli ("ocellos", v.10), se dirige a Licinio como "ocelle" (v.19) y usa los verbos video ("videre", v.12) y perspicio ("perspiceres", v.17); asimismo, el uso del verbo tego ("tegeret") en el verso 10 podría estar aludiendo a lo que se oculta en su 'visión'. 
25. Cfr. OLD (s.v. perspicio).

26. La noción de 'lector modelo' fue propuesta por Eco para designar el tipo de lector que cada texto postula como condición indispensable de su actualización. (Continúa en página 34.)

27. “El cuerpo pornográfico-observa Marzano hablando del consumo del otro en la pornografía- es "aniquilado" por el "exceso": un exceso de intercambios, un exceso de acoplamientos, un exceso de goce; a tal punto que su ganancia inmediata no es nada ás que una completud imagin fantasmática, la de un "objeto sin falla" que oculta la pérdida de la capacidad de desear. Es aniquilado por el vacío: un vacío de caricias, un vacío de abrazos, un vacío de deseos." (2006:67-68). 28. Según Iser, todo texto literario tiene algo de 'performativo', pues no expone ni describe sino que produce reacciones causadas por la realidad, dado que "no poseen objetos que le correspondan exactamente en el 'mundo de la vida', sino que obtiene sus objetos a partir de elementos que se encuentran en ese mundo" (1987:135) (Continúa en página 34.)

29. Al menos esto era así para el ciudadano libre, quien tenía frecuentemente a disposición sexual prostitutas y/o esclavos; estos últimos, en cambio, padeciendo la misma frustración que sufren los sátiros, eran tan pobres "para pagarse una prostituta o un esclavo [que] deben resignarse a masturbarse" (Laqueur, 2007:129). Debido a esto la masturbación era tratada por los poetas como objeto de burla y de ridículo signado por el patetismo de la situación.

30. Cfr. Galeno, De locis affectis, 8.419; citado por Laqueur (2007:110).

31. En la vasija de Niarcos se pueden ver tres sátiros 'amasando' sus enormes falos: Terpekelos ('palo del placer'), Dofios ('el que se la soba', de déphemai) y Psolas ('el que la tiene tiesa', de psolos 'erecto'). La imagen es reproducida por Laqueur (2007:118).

32. El verbo masturbory el sustantivo masturbator sólo están atestiguados en Marcial (9.41.7, 11.104.13, 14.203.2). Etimológicamente, podría tratarse de un compuesto de manus y stupro ('corromper'), o bien sería na forma analógica de manstrupror, que combina manus y struprum ('lascivia') con perpetro ('perpetuar'); cfr. al respecto Laqueur (2007:120).

33. Según Adams (1972:208-211), además del verbo masturbor, existían en latín otros verbos para designar la práctica onanista: frico, sollicito, tango, tracto, ca onanista: frico, sollicito, tango, tracto,
contrecto, trudo, tero, haereo, deglubo. 34. Cfr. OLD (s.v. despuo 1).

35. En el carmen 53 se asocia a Licinio Calvo, quien no sólo era poeta sino también orador, con el movimiento de la mano ("manusque tollens", v. 4) y con la mano ("manusque tollens", v. 4) y con
el miembro viril masculino. El término que se usa para hacer referencia al pene es salaputium, que en principio haría referencia a la baja estatura de Calvo. (Continúa en página 34.)

36. Para el sentido de pronusy supinus como posiciones sexuales, ver Adams (1972:192). verbo puede significar 'mirar atentamente' o 'mirar a través'. ${ }^{25}$ En esta línea interpretativa, y dejando de lado que la interpelación en principio se dirige a Licinio, podemos pensar que más que una mirada lo que se activa es una 'visión', algo que sucede en la mens del lector -así como la figura de Licinio es algo que se constituyó como objeto en la mens del yo poético.

Con los recursos señalados: vocabulario sexual, elipsis y apelación al lector, se inscribe en el cuerpo textual la figura del 'lector modelo' como guía e instrucción para el lector empírico del modo de lectura que el texto requeriría para su adecuada decodificación. ${ }^{26}$

El poema tan sólo sugeriría lo que el lector debe hacer explícito: los amigos, a causa de su juego creativo y el vino, comienzan a tocarse entre sí. No se dice nada más. Pero por el contenido de los versos siguientes se puede sospechar que no llegaron a consumar sexualmente el erotismo despertado entre ellos. El lector no sólo se imagina, allí donde se sugiere pero no se dice, una escena de caricias y palabras dulces dichas en intimidad, sino también una escena, diríamos, de tono más hardcore.

Lo que hay que reponer es lo que hizo el yo poético entre la situación de agotamiento físico que introduce el at del verso 14 y lo que hizo anteriormente. Todo parece indicar que se masturbó en exceso pensando en Licinio. ${ }^{27}$ Este es el acto sexual, la escena 'porno-gráfica' que, como lectores, debemos (de) construir, actuar, 'performativizar'. ${ }^{28}$

El sexo solitario es un tipo de acto sexual que tiene su historia cultural y literaria. En el mundo grecolatino, donde el encuentro sexual era un caso fácil, el onanismo no representaba un problema para el hombre común y sólo los poetas satíricos y eróticos hacían de él un tema literario. ${ }^{29}$ Desde un punto de vista fisiológico, filósofos y médicos incluían el tema de la masturbación en la problemática más general de la administración de los placeres: los excesos sexuales eran potencialmente riesgosos, porque la constante pérdida del flujo seminal "ponía en dificultades la economía corporal y el bienestar moral de sus adeptos" (Laqueur 2007:108). Galeno, sin embargo, aconsejaba evacuar el exceso de esperma mediante la masturbación como forma de aliviar alguna perturbación del ánimo. ${ }^{30}$ En Grecia la práctica masturbatoria era aludida con el verbo déphemai, ${ }^{31}$ mientras que en Roma los términos masturbor y masturbator aparecen durante el período en que impera la dinastía Flavia, aunque sigue sin quedar claro cuál es su origen. ${ }^{32}$

Si bien en el carmen 50 de Catulo no aparece el verbo masturbor ni sus sinónimos, ${ }^{33}$ sí estarían explícitamente mencionados todos los síntomas de un agotamiento post-masturbatorio ("defessa labore membra", v.14; "semimortua lectulo iacebant", v.15; "meum dolorem", v.17).

Podemos establecer una última analogía. En el verso 19 se usa el verbo despuo ("cave despuas"). El yo poético aconseja a Licinio que no menosprecie su deseo sexual. Si bien el verbo tiene esta acepción (como sinónimo de sperno), su sentido concreto es el de 'escupir hacia abajo' ${ }^{34}$ El poeta pide en retribución lo que él por el momento ha agotado: la potencia eréctil del salaputium de Licinio Calvo. ${ }^{35}$ Por esto, no le estaría solicitando al amigo una eyaculación propia de la posición del pronus, sino una eyaculación supina, o sea la de aquel que acostado boca arriba es masturbado o incluso 'irrumado' por otro. ${ }^{36}$ 
Catulo, como poeta fáunico, ${ }^{37}$ se inscribiría en esta 'apertura' de la representación del acto sexual, por lo que el carmen 50 podría ser leído no tanto como un poema erótico sino como un poema 'porno-gráfico'.

\section{IV}

Respetando el tono lírico, el buen gusto literario y los códigos del género, así como acudiendo al recurso alejandrino de la alusión, Catulo podría estar sugiriendo el modo de lectura del carmen 50, por lo que el poema debería de leerse no sólo en clave erótica sino también en clave sexual, donde por sexual hay que entender, por lo menos, la insinuación de una escena de sexo.

En términos alegóricos, la figura de Licinio Calvo, en tanto poeta neotérico, puede ser el espejo en el que el poeta se mira a sí mismo. Se establecería así una íntima relación entre creación poética y voluptuosidad, asociadas a las intensas sensaciones corporales que la actividad poética despierta. En este sentido, la creación poética se viviría y se gozaría 'sexualmente'.

Poeta genital, requiere de su amigo un amor genital. Ya no más roces, ya no más imposibilidades de satisfacción. El poeta puede dar sólo lo que tiene para dar: versitos lúbricos. Siguiendo la lógica del do ut des, quisiera que Licinio lo compense con lo mismo: versos-eyaculados, pegajosos, venéreos. En definitiva, que Licinio lo retribuya con su 'poema-pene' sementoso:

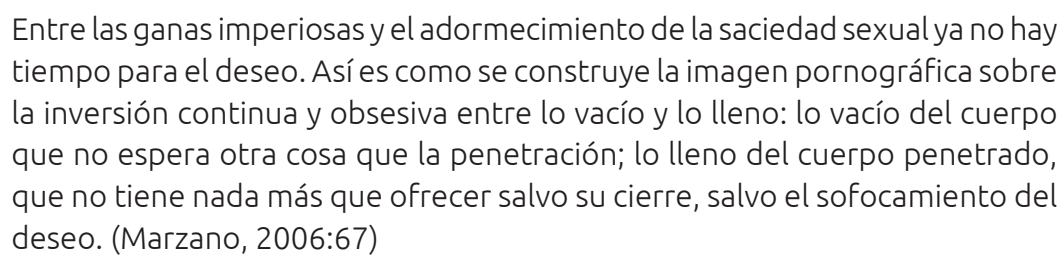

El semen que, según nuestra lectura, el yo poético habría derramado hasta quedar exhausto pensando en su amigo circuló metafóricamente desde su pene hasta su boca, la cual 'eyecta' con ardor palabras seminales que dirigidas a su colega espera tracen el camino inverso. De los oídos como instancia receptiva a su stylus carnal y venoso, a partir del cual el poeta pretende recuperar todo aquello que habría desperdiciado durante la noche: versos, verbos, besos.
37. Respecto de la experiencia sexual, Lissardi señala que en la cultura occidental siempre han operado dos paradigmas: el paradigma amoroso y el paradigma que él llama fáunico. El primero gestiona una imagen espiritual del eros, mientras que el segundo privilegia "el apetito sexual, el deseo, la curiosidad sexual, la voluptuosidad, como vectores esencialmente enriquecedores de la peripecia humana" (Lissardi 2013:13). 


\section{Notas}

26 La noción de 'lector modelo' fue propuesta por Eco para designar el tipo de lector que cada texto postula como condición indispensable de su actualización. El 'lector modelo' es un posicionamiento del lector en el tejido textual, cuya función consiste en colaborar con la construcción del sentido que todo texto requiere para funcionar como tal. La 'necesariedad' de este principio pragmático de cooperación interpretativa reside en que "un texto es un mecanismo perezoso (o económico) que vive de la plusvalía de sentido que el destinatario introduce en él (...). Un texto quiere que alguien lo ayude a funcionar" (Eco, 1981:76). (Viene de página 32.)

28 Según Iser, todo texto literario tiene algo de 'performativo', pues no expone ni describe sino que produce reacciones causadas por la realidad, dado que "no poseen objetos que le correspondan exactamente en el 'mundo de la vida', sino que obtiene sus objetos a partir de elementos que se encuentran en ese mundo" (1987:135). Por ello, configura y proyecta el esbozo de una estructura objetiva mediante la que se apela al lector, marcando las posibilidades de decodificación de cada texto, al garantizar un "espacio de juego de posibilidades de actualización" (Iser, 1987:134), ya que su sentido no radica en el mundo sino en el proceso de lectura que posibilita. (Viene de página 32.)

35 En el carmen 53 se asocia a Licinio Calvo, quien no sólo era poeta sino también orador, con el movimiento de la mano ("manusque tollens", v. 4) y con el miembro viril masculino. El término que se usa para hacer referencia al pene es salaputium, que en principio haría referencia a la baja estatura de Calvo. Pero el término también sería un sinónimo de mentula, palabra por antonomasia en la cultura latina para designar al miembro masculino (cfr. Adams 1972:65), aunque no hay unánime acuerdo sobre su significado. Podría, según Soler Ruiz (2000:80), ser parafraseada como mentula salax, 'pito lascivo'. Rizzo (1992:176) estima que es un compuesto vulgar de salaxy putium, el diminutivo de putum, 'pene'. Teniendo en cuenta entonces la profesión de orador y la baja estatura de Calvo así como el registro vulgar del término, se podría traducir salaputium disertum (Cat.53.5) como 'elocuente pitito lascivo'. (Viene de página 32.) 


\section{Bibliografía}

» Adams, J. (1972). The Latin Sexual Vocabulary. Baltimore: Duckworth.

" Barthes, R. (2003). El placer del texto y Lección inaugural. Buenos Aires: Siglo XXI.

» Borzi, C. (2012). "Gramática cognitiva-prototípica: conceptualización y análisis del nominal", Fundamentos en Humanidades 21.1, 99-126.

» Cabello Pino, M. (2012). "La corriente científico-filosófica de la enfermedad de amor en la Grecia clásica: Hipócrates, Platón y Aristóteles”, AnMal Electrónica 33, 29-43.

» Eco, U. (1981). Lector in fabula. La cooperación interpretativa en el texto narrativo. Barcelona: Lumen.

"Eco, U. (1996). Seis paseos por los bosques narrativos. Barcelona: Lumen.

» Eco, U. (1998). Los límites de la interpretación. Barcelona: Lumen.

» Fordyce, C. (1961). Catullus. Oxford: Oxford University Press.

"Fraschini, A. (1966). "Contribución al estudio comparativo de la lírica alejandrina y la de los neotéricos. Calímaco y Catulo", AFC 9, 157-195.

» Galán, L. (2013). Catulo. Poesía completa. Buenos Aires: Colihue.

» García Rodríguez, A. (2001). Desentrañando 'lo pornográfico'. En: http://www. analesiie.unam.mx/ index.php/analesiie/article/view/2088/2892; obtenido: 15/10/2016.

» Givón, T. (1993). "Coherence in text, coherence in mind", Pragmatics and Cognition $1.2,171-227$.

» Hydé, H. (1969). Historia de la pornografía. Buenos Aires: La Pléyade.

"Iser, W. (1987). "La estructura apelativa de los textos". En: Rall D. (comp.), En busca del texto. Teoría de la recepción literaria. México: UNAM, 133-148.

» Laqueur, Th. (2007). Sexo solitario: Una historia cultural de la masturbación. Buenos Aires: FCE.

» Liddell, H., Scott, R. y Jones, H. (1996). A Greek-English Lexicon. Oxford: Oxford University Press.

» Lissardi, E. (2013). La pasión erótica: del sátiro griego a la pornografía en Internet. Buenos Aires: Paidós.

» Loth, D. (1969). Pornografía, erotismo y literatura. Buenos Aires: Paidós.

» Lyne, R. (2007). "The Neoteric Poets". En: Haig Gaisser J. (ed.), Oxford Readings in Catullus. Oxford: University Press, 109-140.

" Manwell, E. (2007). "Gender and Masculinity". En: Skinner M. (ed.), A Companion to Catullus. USA/UK/Australia: Blackwell, 111-128.

" Marzano, M. (2006). La pornografía o el agotamiento del deseo. Buenos Aires: Manantial.

» Merrill, E. (ed.) (1893). Catullus. Boston and London: Ginn \& Co.

» Rizzo, T. (trad.) (1992). Catullo. Le Poesie. Roma: Newton Compton editori.

» Schuster, M. (ed.) (1958). Catulli Veronensis Liber. Lipsiae: Teubner. 
"Soler Ruíz, A. (trad.) (2000). Catulo. Poemas. Madrid: Gredos.

» The Oxford Latin Dictionary (1968-1982) [=OLD]. Oxford: Clarendon Press.

"Uría Varela, J. (1997). Tabú y eufemismo en latín. Amsterdam: A. M. Hakkert Publisher.

» van Dijk, T. (1985). "Semantic Discourse Analysis". En: van Dijk, T. (ed.), Handbook of discourse analysis - Dimensions of Discourse. Orlando: Florida, 103-136.

» Wiseman, T. (2007). "A World Not Ours". En: Haig Gaisser J. (ed.), Oxford Readings in Catullus. Oxford: University Press, 343-355.

» Zaina, E. (1997). "Catulo 44, 50 y 51: el cuerpo atravesado por la literatura”, Emerita 65.2, 303-307.

»Zimmermann, B. (2003). "Sexualidad y erotismo en la literatura griega", Ordia Prima $2,155-167$ 